\title{
Human colonic intraepithelial lymphocytes suppress in vitro immunoglobulin synthesis by autologous peripheral blood lymphocytes and lamina propria lymphocytes
}

\author{
G K Sachdev, H R Dalton, P Hoang, M C DiPaolo, B Crotty, D P Jewell
}

\begin{abstract}
Human colonic intraepithelial lymphocytes have been shown to suppress the proliferation of autologous lamina propria lymphocytes and allogeneic peripheral blood mononuclear cells. This study has shown that, in vitro, intraepithelial lymphocytes suppress IgA and total immunoglobulin synthesis (but not IgG or IgM production) by autologous peripheral blood and lamina propria lymphocytes. This down regulation of IgA production is mediated by a soluble factor secreted by the intraepithelial lymphocytes. There is no difference in immunoglobulin down regulation by intraepithelial lymphocytes of control subjects and patients with inflammatory bowel disease.

(Gut 1993; 34: 257-263)
\end{abstract}

Human intraepithelial lymphocytes (IEL) are found on the basement membrane between the enterocytes and have a close spatial relationship with luminal antigens, including many potentially pathogenic organisms. Although phenotypically most IEL are $\mathrm{CD} 3^{+} \mathrm{CD}^{+},{ }^{1-5}$ the function of these cells, especially in humans, is not well defined. This is mainly because of the difficulty in isolating IEL in samples adequate in size and purity. A method of isolating IEL from resected human colon has recently been developed, ${ }^{6}$ the isolated IEL preparation having a similar distribution of phenotypes as determined by tissue section. The human colonic IEL thus isolated were shown to suppress the lectin driven proliferation of autologous lamina propria lymphocytes. ${ }^{6}$ In another recent study, IEL isolated from human small intestine suppressed the proliferative response of allogeneic peripheral blood lymphocytes (PBL). ${ }^{7}$ The effect of human IEL on immunoglobulin (lg) production has also been studied, but with conflicting results. Greenwood et al $l^{1}$ showed an immunoregulatory effect of IEL on pokeweed mitogen stimulated Ig synthesis by peripheral blood PBL. IEL helped Ig synthesis by PBL when added in low numbers, but increasing the proportion of IEL in the cocultures suppressed the secretion of IgA and IgM classes of Ig. However, Smart et $a l^{\times}$ failed to confirm this effect of IEL using a similar system.

This study aimed to evaluate further the suppressor function of human colonic IEL and, in particular, to assess the effect of IEL on Ig production by PBL and lamina propria lymphocytes (LPL) in controls and patients with inflammatory bowel disease.

\section{Methods}

PATIENTS

For the PBL studies, colonic resection specimens were collected from nine control patients (carcinoma (7), diverticular disease (2); 4 men and five women, with a mean (SD) age of 61 (10) years) and from nine patients with inflammatory bowel disease (ulcerative colitis (7), and Crohn's disease (2), four men and five women with a mean age of 39 (14) years)

For the LPL studies, colonic tissue was used from eight control patients (carcinoma (5), idiopathic constipation (1), appendicular abscess (normal caecum) (1), and 'cap polyposis' (1); five men and three women with a mean age of 55 (17) years. Six patients with inflammatory bowel disease were studied (Crohn's disease (4) and with ulcerative colitis (2); mean age 36 (18) years.

Specimens from the control patients were taken at least $7 \mathrm{~cm}$ away from any macroscopic lesion and were subsequently shown to be histologically normal. In the patients with inflammatory bowel disease, uninflamed or the least inflamed parts of the specimen were collected.

ISOLATION OF IEL

The method used was the same as that described by Hoang et al. ${ }^{6}$ In brief, the specimen was washed three times with Hanks balanced salt solution (HBSS) without calcium and magnesium (Flow, Irvine, Scotland) containing penicillin $100 \mathrm{U} / \mathrm{ml}$ and gentamicin $50 \mu \mathrm{g} / \mathrm{ml}$. The mucosa was carefully dissected and washed several times in the same buffer. The mucosal strips were incubated for $15-20$ minutes at $37^{\circ} \mathrm{C}$ in $1 \mathrm{mM}$ dithiothreitol (DTT, Sigma) in RPMI 1640 with L-glutamine and $25 \mathrm{mM}$ Hepes buffer supplemented with $10 \%$ fetal calf serum (FCS) and antibiotics, as above. After washing the mucosal strips with HBSS a further three times, they were incubated with $0.75 \mathrm{mM}$ disodium EDTA (prepared in HBSS and supplemented with $10 \%$ FCS, antibiotics, and $10 \mathrm{mM}$ Hepes buffer) in a shaking water bath at $37^{\circ} \mathrm{C}$ at 160 oscillations per minute for 35 minutes. The supernatant was collected and the mucosal strips were incubated twice more with $0.75 \mathrm{mM}$ EDTA for 30 minutes (the supernatant was collected between each incubation). The supernatants were pooled and centrifuged at $500 \mathrm{~g}$ for 8 minutes and the cell pellet was washed three times with RPMI 1640 with FCS $(10 \%)$. The cells were finally resuspended in RPMI and stored overnight at $4^{\circ} \mathrm{C}$. IEL were separated from 
the epithelial cells by passing the suspension through a glass-wool column (Sigma). The filtrate was centrifuged and the IEL containing cell pellet was further purified by performing a two step Percoll gradient of $44 \%$ and $67 \cdot 5 \%$ at $800 \mathrm{~g}$, as previously described. ${ }^{9}$ IEL were recovered from the interface, washed, and suspended in RPMI with $10 \%$ FCS to a final concentration of $1 \times 10^{6}$ cells $/ \mathrm{ml}$.

\section{ISOLATION OF LPL}

In some experiments LPL were isolated from the same mucosal strips, using a modification of the method described by Bull and Bookman. ${ }^{10}$ Briefly, mucosal strips from the above experiment were incubated twice more with $5 \mathrm{mM}$ EDTA in a shaking water bath at $37^{\circ} \mathrm{C}$, washed with HBSS, and the supernatant discarded. The strips were subsequently minced into fine pieces and incubated overnight in a shaking water bath at $37^{\circ} \mathrm{C}$ with $100 \mathrm{ml}$ of RPMI containing $10 \%$ FCS, antibiotics, and $30 \mathrm{mg}$ Clostridium histolyticum collagenase (Boehringer Mannheim $\mathrm{GmbH}$, Germany). At the end of the incubation, the digestate was mixed vigorously, filtered through a $100 \mu \mathrm{m}$ nylon mesh (Lockertex, Warrington, UK), and washed a further three times in HBSS. LPL were recovered after centrigugation over a Ficoll-Paque (Pharmacia, LKB, Uppsala, Sweden) gradient at $500 \mathrm{~g}$, washed three times in RPMI with $10 \%$ FCS, and resuspended to a final concentration of $1+10^{6}$ cells/ml.

immunoglobulin by normal peripheral blood

lymphocytes from control subjects $(n=9)$ and patients with inflammatory bowel disease $(\boldsymbol{n}=9) .0 \cdot 5 \times 10^{6}$ peripheral blood lymphocytes were cultured for 9 days with or without $0.5 \times 10^{6}$ intraepithelial lymphocytes, both in the absence or presence of pokeweed mitogen. The results are expressed as ng/ ml of culture supernatant $\left(5 \times 10^{5}\right.$ cells $\left./ \mathrm{ml}\right)$. once with RPMI with $10 \%$ FCS before suspending them in RPMI with $10 \%$ FCS to a concentration of $1+10^{6}$ cells $/ \mathrm{ml}$.

\section{PHENOTYPIC ANALYSIS}

IEL were stained with monoclonal antibodies (Simultest helper/suppressor - CD4/CD8, Becton-Dickinson) and were analysed by flow cytometry (FACScan, Becton Dickinson, Sunnyvale CA, USA) as previously described. The viability of the cells were assessed using $0 \cdot 1 \%$ Trypan blue.

\section{CELL CULTURE AND COCULTURE}

$0.5 \times 10^{6} \mathrm{PBL}$ were cultured in triplicate at $37^{\circ} \mathrm{C}$ with $5 \% \mathrm{CO}_{2}$ for 9 days, in the presence or absence of pokeweed mitogen (Gibco) at a final concentration of 1 in 100 . In initial experiments $(\mathrm{n}=4), 0 \cdot 1 \times 10^{6}$ or $0 \cdot 2 \times 10^{6}$ IEL were added to PBL. In all subsequent experiments $0.5 \times 10^{\circ}$ IEL were added to $0.5 \times 10^{6} \mathrm{PBL}$ to a final volume of $1 \mathrm{ml}$.

In a further series of experiments, $0.5 \times 10^{\circ}$ LPL were used as responder cells (instead of PBL) and similar cocultures with $0.5 \times 16^{6}$ IEL were performed as described above. At the end of the incubation period, the supernatant was collected from all the cultures, centrifuged, and stored at $-20^{\circ} \mathrm{C}$ for subsequent Ig analysis by ELISA.

In 10 of the above patients (five control and five inflammatory bowel disease) proliferation suppression studies were performed simultaneously, as previously described. ${ }^{6}$ Briefly, $5 \times 10^{4} \mathrm{LPL}$ with $10 \mu \mathrm{g} / \mathrm{ml}$ of phytohaemag glutinin were cultured with or without $1 \times 10^{5}$ IEL in 96-well plates for 6 days. Sixteen hours before the end of the culture, $1 \mu \mathrm{Ci}^{3}[\mathrm{H}]$ methyl thymidine (Amersham Laboratories, Amersham, UK) was added to each well. The cells were then harvested onto filter paper discs and suspended in $10 \mathrm{ml}$ of scintillation fluid (Optiphase Safe, LKB, Poole, Dorset, UK) and counted in a scintilation counter (1215 Rackbeta scinitilation counter, LKB).

In two experiments, $1 \times 10^{6} / \mathrm{ml}$ IEL were cultured alone for 5 days. The supernatant was then collected, centrifuged, and filtered through a 22 $\mu \mathrm{m}$ filter. $0.5 \times 10^{6} \mathrm{PBL}$ (isolated from normal subjects) were cultured with or without $0.5 \mathrm{ml}$ of IEL supernatant. After 9 days of incubation at $37^{\circ} \mathrm{C}$ with $5 \% \mathrm{CO}_{2}$, the supernatant was collected and stored at $-20^{\circ} \mathrm{C}$ for subsequent Ig assay.

ASSAY OF IG BY ELISA

A standard ELISA method as described by Wu et $a l^{11}$ was used for measuring total $\mathrm{Ig}, \operatorname{IgG}, \operatorname{IgA}$, and $\operatorname{IgM}$ in the culture supernatant. Briefly, polyvalent goat anti-human Ig (Sigma) and monoclonal rabbit anti-human IgG, IgA, and IgM (Dakopatts) were diluted in $0.01 \mathrm{M}$ bicarbonate buffer ( $\mathrm{pH} \mathrm{9.6)}$ to a concentration of $4 \mu \mathrm{g} / \mathrm{ml}$. $200 \mu \mathrm{l}$ of this solution were added to each well in separate 96-well plates, which were then incubated overnight at $4^{\circ} \mathrm{C}$. The next day the plates were washed five times with PBS containing $0 \cdot 1 \%$ Tween 20 (PBS-T), and $150 \mu \mathrm{l}$ 


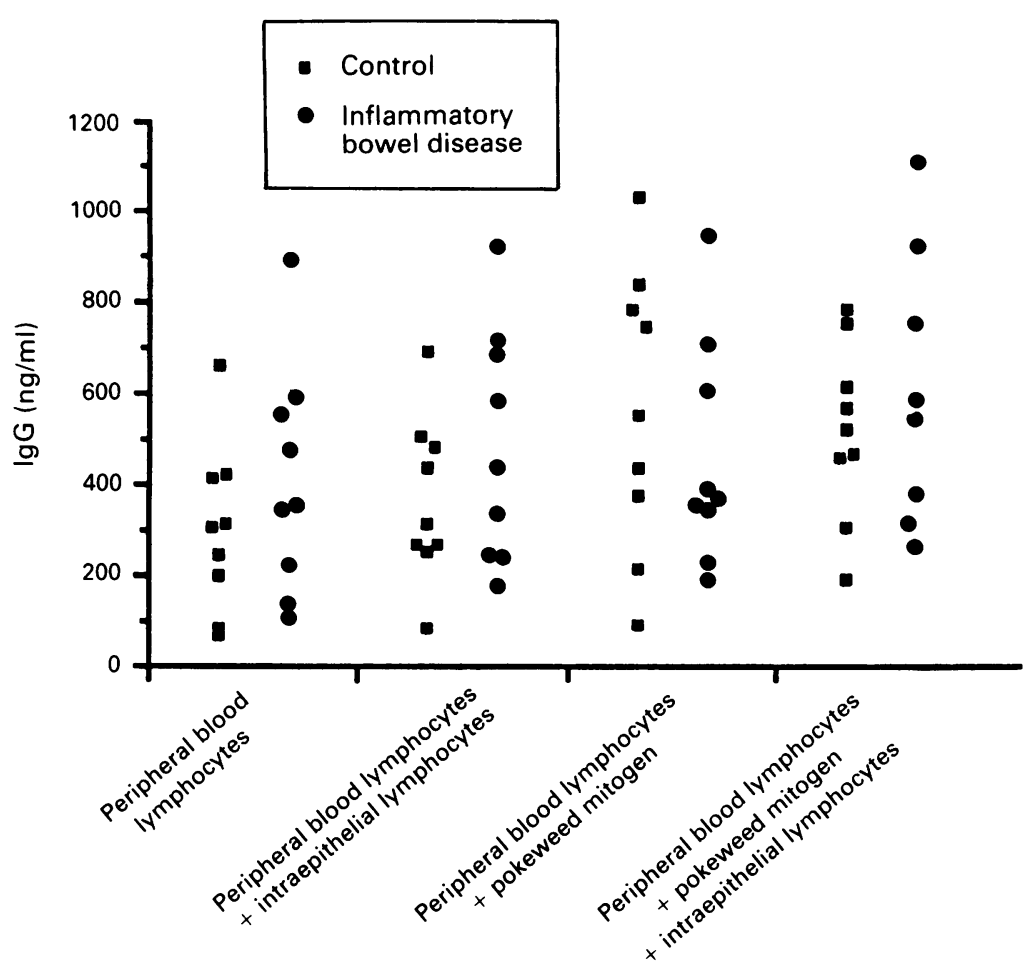

Figure 2: Secretion of IgG by normal control subjects $(n=9)$ and patients with inflammatory bowel disease $(n=9)$. (See legend to Figure 1.)

Figure 3: Secretion of IgA by normal peripheral blood lymphocytes from control subjects $(n=9)$ and patients with inflammatory bowel disease $(n=9)$. (See legend to Figure 1.)

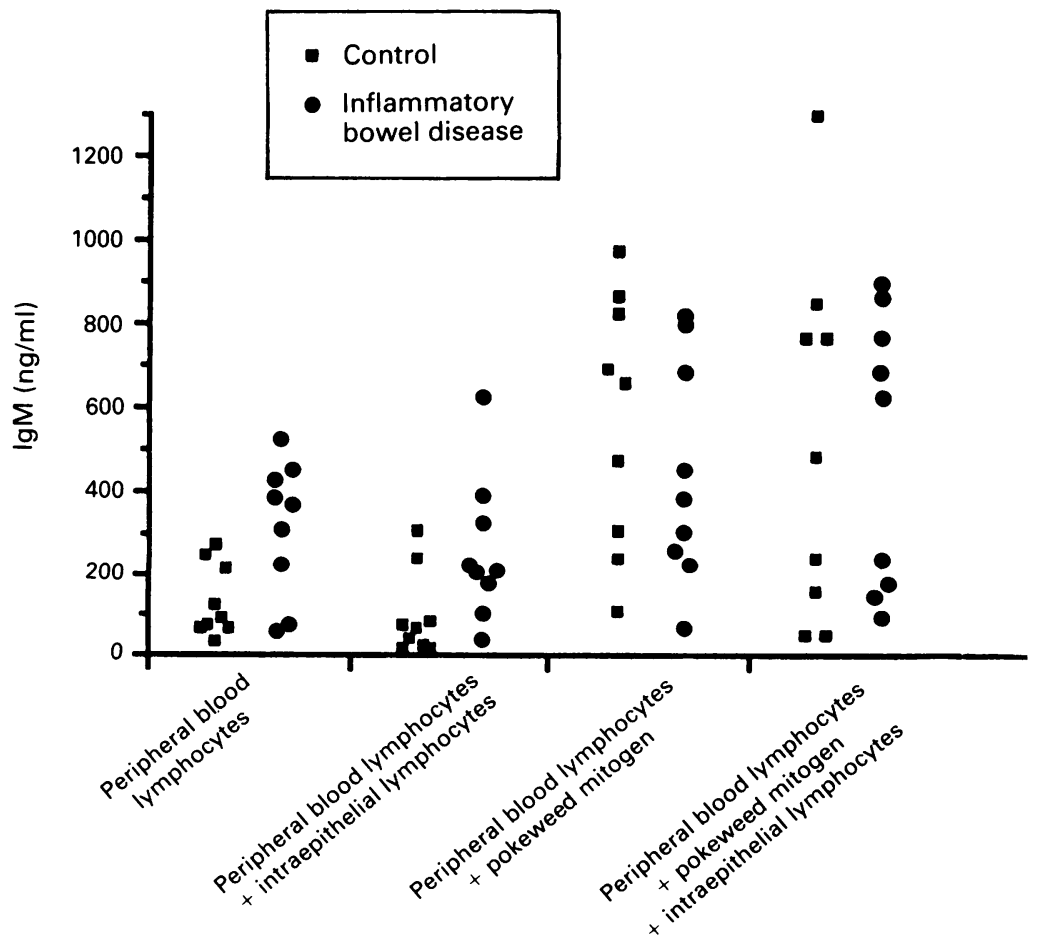
Birmingham, UK) were added. The incubation was performed overnight at $4^{\circ} \mathrm{C}$. The plates were washed again with PBS-T. Peroxidase conjugated goat polyvalent anti-human Ig (Sigma) or monovalent rabbit anti-human $\operatorname{IgG}, \operatorname{IgA}$, and $\operatorname{IgM}$ (Dakopatts) were diluted 1 in 1000 in PBS. $100 \mu \mathrm{l}$ aliquots of these antibodies were added to each well and the plates were incubated for 1 hour at room temperature. A fresh substrate was prepared by dissolving $8 \mathrm{mg}$ of OPD (Dakopatts) in $12 \mathrm{ml}$ of $0.1 \mathrm{M}$ citrate buffer ( $\mathrm{pH} \mathrm{5.6)}$ containing $5 \mu \mathrm{l}$ of $\mathrm{H}_{2} \mathrm{O}_{2}(30 \% \mathrm{v} / \mathrm{v})$. After washing the plates, $100 \mu \mathrm{l}$ of substrate solution were added to each well and the reaction was stopped after 2 minutes by adding $150 \mu \mathrm{l}$ of $1 \mathrm{M} \mathrm{H}_{2} \mathrm{SO}_{4}$. The plates were read within 5 minutes at $492 \mathrm{~nm}$ on a Titertek Multiscan reader. A standard curve was constructed and the values of the various immunoglobulins were calculated and expressed as $\mathrm{ng} / \mathrm{ml}$ of supernatant.

CALCULATION OF THE SUPPRESSOR INDEX (SI)

The suppressor index was calculated for both Ig secretion and proliferation using the following formulae:

$$
\text { Immunoglobulin } \mathrm{SI}=\left[\frac{1-\mathrm{PBL}+\mathrm{IEL}}{\mathrm{PBL}}\right]-100
$$

where $\mathrm{PBL}=$ immunoglobulin secreted by $\mathrm{PBL}$ alone $(\mathrm{ng} / \mathrm{ml})$ and $\mathrm{PBL}+\mathrm{IEL}=$ immunoglobulin secreted by PBL in the presence of IEL $(\mathrm{ng} / \mathrm{ml}$ )

$$
\text { Proliferation SI }=\left[1-\frac{\text { LPL }+ \text { PHA }+ \text { IEL }}{\text { LPL }+ \text { PHA }}\right]-100
$$

where $\mathrm{LPL}+\mathrm{PHA}=$ proliferation of $5 \times 10^{4}$ autologous LPL plus $10 \mu \mathrm{g} / \mathrm{ml}$ PHA (dpm) and $\mathrm{LPL}+\mathrm{PHA}+\mathrm{IEL}=$ proliferation of $5+10^{4}$ autologous LPL plus $10 \mu \mathrm{g} / \mathrm{ml}$ PHA plus $1 \times 10^{5} \mathrm{IEL}$ (dpm)

Positive SI values indicated suppression, and negative values help.

\section{STATISTICS}

The results were analysed using the MannWhitney $U$ test; $p<0.05$ was taken as significant.

\section{ETHICS}

Approval for the study was given by Central Oxford Research and Ethics Committee.

\section{Results}

\section{CELL POPULATION CHARACTERISTICS}

The yields of IEL were mean (SD), $0.49(0.08)$ and $0.50(0.07) \times 10^{6} / \mathrm{g}$ of tissue from the control subjects and inflammatory bowel disease patients respectively. The viability of IEL $>90 \%$ in all cases, and the mean (SD) CD4/CD8 ratios were $0.20(0.14)$ for control and $0.19(0.086)$ for inflammatory bowel disease subjects. Populations of IEL with a CD4/CD8 ratio $>0.45$ were discarded. The yield of LPL was $2 \cdot 1(0 \cdot 4) \times 10^{6} / \mathrm{g}$ tissue and the viability was $>90 \%$ in all subjects.

\section{IG SYNTHESIS BY PBL}

Compared with control PBL, unstimulated PBL from patients with inflammatory bowel disease produced significantly more total $\mathrm{Ig}, \operatorname{IgA}$, and $\operatorname{IgM}(\mathrm{p}<0.05)$. In control subjects pokeweed mitogen stimulated secretion of total Ig, IgG, and IgM. In contrast, there was a tendency for $\operatorname{IgA}$ production to be suppressed. In inflammatory bowel disease patients, however, pokeweed 


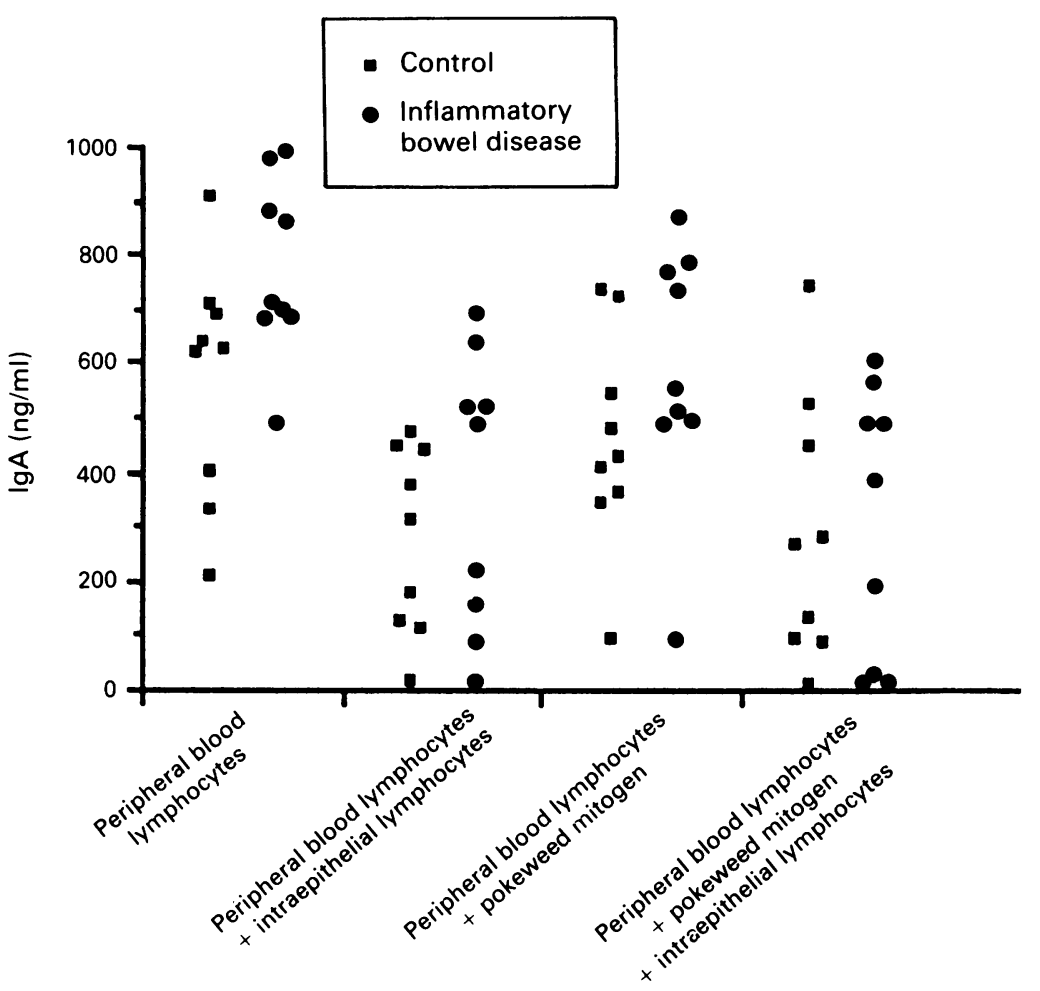

Figure 4: Secretion of IgM by normal peripheral blood lymphocytes from control subjects $(n=9)$ and patients with inflammatory bowel disease $(n=9)$. (See legend to Figure 1.)

Unstimulated PBL from inflammatory bowel disease patients tended to produce less total Ig when cultured with IEL, although this difference was not significant. Secretion of IgA by PBL from these patients was suppressed by IEL both in the absence $(711 \mathrm{ng} / \mathrm{ml}$ (range $487-993)$ to $486 \mathrm{ng} / \mathrm{ml}$ (range $0-693) ; \mathrm{p}<0.05$ ) and presence $(551 \mathrm{ng} / \mathrm{ml}$ (range $99-871$ ) to $387 \mathrm{ng} / \mathrm{ml}$ (range 0 $602) ; \mathrm{p}<0.05$ ) of pokeweed mitogen. The production of IgG and IgM by PBL was not altered by IEL (Figs 2 and 3).

Although there was considerable variability in the amount of Ig produced by PBL from both control and inflammatory bowel disease patients, IgA production was suppressed in 17 of 18 assays (Figs 5 and 6).

\section{IG SECRETION BY LPL/IEL COCULTURES}

Taking the patients as a whole $(n=14)$, IEL significantly suppressed secretion of $\operatorname{IgA}$ (from a median (range) of $1369 \mathrm{ng} / \mathrm{ml}(1216-1742)$ to $1051 \mathrm{ng} / \mathrm{ml}(174-1428) ; \mathrm{p}<0.005)$ and total Ig (from $3130 \mathrm{ng} / \mathrm{ml}(2014-3956)$ to $2604 \mathrm{ng} / \mathrm{ml}$ (1739-3566); $\mathrm{p}<0.05$ ) by unstimulated LPL. In addition, IEL significantly suppressed secretion of $\operatorname{IgA}(1270(970-1598)$ to $911(94-1319) \mathrm{ng} / \mathrm{ml}$, $\mathrm{p}<0.05)$ and total Ig (2559 (1928-3890) to 2073

mitogen did not significantly effect the secretion of immunoglobulins by PBL (Figs 1-4).

IG SECRETION BY PBL/IEL COCULTURES

In initial experiments, the effect of varying IEL/ PBL ratios was examined. Although some suppression occurred at a 1:5 ratio, maximal effects were seen at a ratio of $1: 1$. An IEL/PBL ratio of $1: 1$ was therefore used in all subsequent experiments.

In control subjects, IEL significantly $(\mathrm{p}<0.05)$ suppressed secretion of total Ig from a median of $1066 \mathrm{ng} / \mathrm{ml}$ (range 707-1325) to 771 $\mathrm{ng} / \mathrm{ml}$ (range 356-1093), and IgA from a median of $629 \mathrm{ng} / \mathrm{ml}$ (range 213-960) to $315 \mathrm{ng} / \mathrm{ml}$ (range 18-451). IEL had no effect on the secretion of these immunoglobulins by PBL incubated with pokeweed mitogen (Figs 1-4).

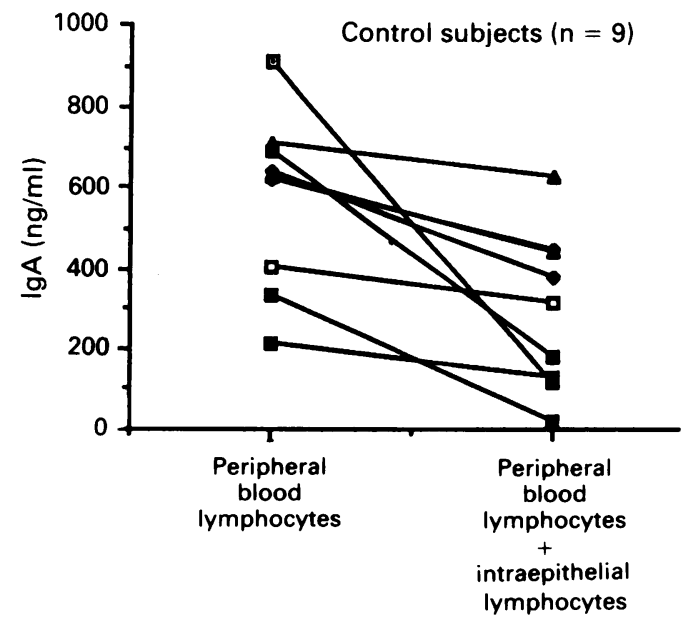

Figure 5: Suppression of secretion of IgA by peripheral blood lymphocytes from control subjects when intraepithelial are added in a ratio of $1: 1(p<0.05)$. The results are expressed as $\mathrm{ng} / \mathrm{ml}$ of culture supernatant (peripheral blood lymphocytes $5 \times 10^{5}$ cells $/ \mathrm{ml} \pm$ intra-epithelial lymphocytes $5 \times 10^{5}$ cells $m l)$.
(1846-2906) $\mathrm{ng} / \mathrm{ml}, \mathrm{p}<0.05$ ) by LPL cultured with pokeweed mitogen, as shown in Figures 7 and 8 . However, there were no statistical differences in the amount of suppression of IgA or tota Ig by IEL in the control group and the patients with inflammatory bowel disease. As with PBL, IEL had no significant effect on the secretion of IgG or IgM by LPL (data not shown).

\section{SUPPRESSION INDICES (SI)}

\section{LPL proliferation experiments}

In 10 experiments, IEL mediated suppression of LPL proliferative responses was compared simultaneously with IEL mediated suppression of IgA and total Ig synthesis by PBL.

In all 10 subjects the proliferative response of LPL to $10 \mu \mathrm{g} / \mathrm{ml}$ of phytohaemagglutinin was

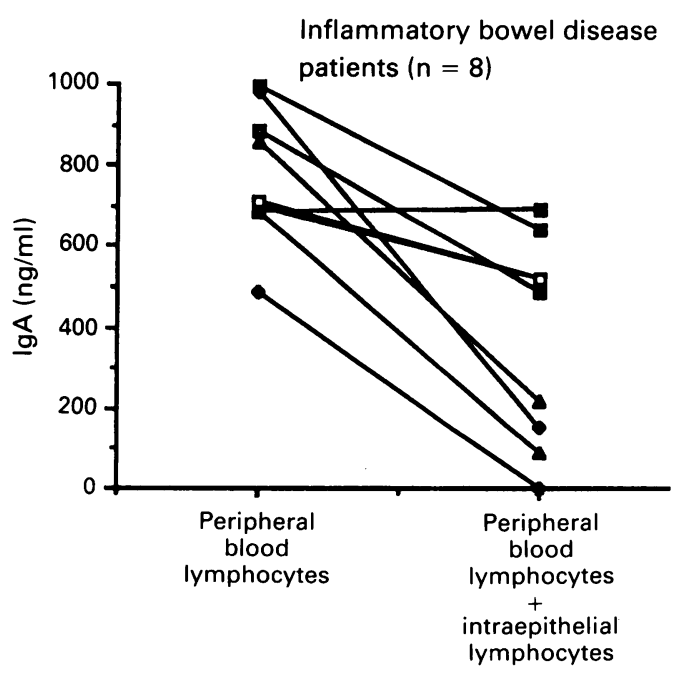

Figure 6: Suppression of secretion of IgA by peripheral blood lymphocytes from patients with inflammatory bowel disease when intraepithelial lymphocytes are added in a ratio of $1: 1$. (See legend to Figure 5 .) 
suppressed by IEL from a median of $62376 \mathrm{dpm}$ (24681-132785) to $30411 \mathrm{dpm}$ (59710-8632), $\mathrm{p}<0.05$. The median $\mathrm{SI}$ in these proliferative studies was $+53 \cdot 5 \%$ (range $+30 \cdot 9$ to $+98 \cdot 4$ ).

In the same subjects, simultaneous experiments showed that IEL also suppressed IgA and total Ig secretion by PBL (in all experiments), the median SIs being $+40.0 \%$ (range $+21 \cdot 6$ to 86.8 ) and $+33 \cdot 1 \%$ (range $+7 \cdot 9$ to $+71 \cdot 4$ ) respectively. Despite the magnitude of the suppression being similar, there was no linear relationship between the suppressive activity of IEL on the proliferative responses of LPL and IgA or total Ig production.

\section{Supernatant experiments}

Supernatant from 5 days' culture of IEL when added to PBL from healthy volunteers $(n=5)$ suppressed the secretion of $\mathrm{Ig}$ as shown in Figures 9 and 10. There was, however, no effect on the secretion of $\operatorname{IgG}$ or $\operatorname{IgM}$ (data not shown).

\section{Discussion}

IEL constitute a discrete compartment of the immune system. Phenotypically, most IEL are $\mathrm{CD}^{+}$(suppressor/cytotoxic) $\mathrm{T}$ lymphocytes. The CD4/CD8 ratio of isolated IEL in the present study showed a similar distribution to that seen in tissue section. A recent study failed

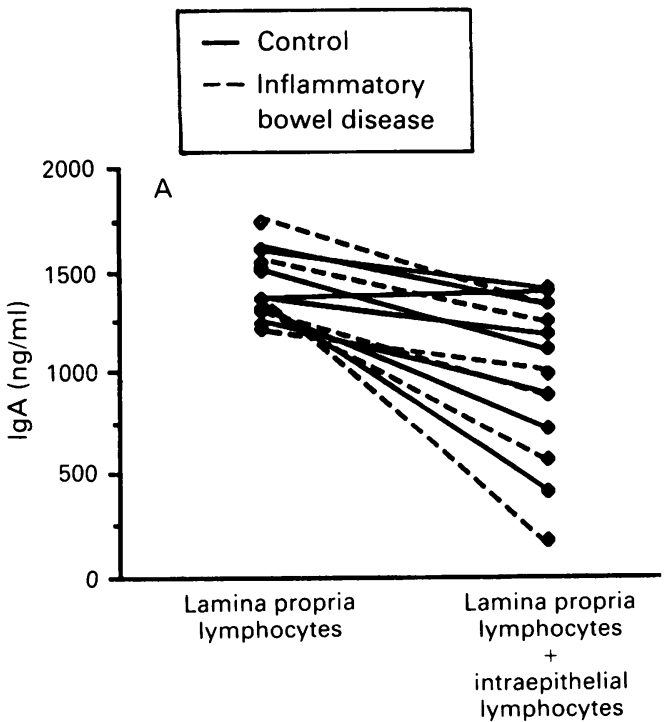

Figure 7: Effect of intraepithelial on secretion of $\operatorname{IgA}$ by lamina propria lymphocytes from eight control subjects and six patients with inflammatory bowel disease, cultured with or without pokeweed mitogen. (Lamina propria lymphocytes $5 \times 10^{5}$ cells \pm intraepithelial lymphocytes $5 \times 10^{5}$ cells. ) There was significant suppression of IgA secretion and total Ig secretion (Fig 8) both in the presence and absence of pokeweed mitogen, but no difference between control subjects and patients with inflammatory bowel disease. The results expressed as $\mathrm{ng} / \mathrm{ml}$ of culture supernatant. to show any cytotoxic activity in a population of human IEL, a finding confirmed by Hoang, Dalton, and Jewell (unpublished observations). Suppressor activity of human colonic IEL to autologous LPL has recently been shown. ${ }^{6}$ The present study shows that IEL are also able to suppress immunoglobulin synthesis by autologous PBL as well as LPL.

There are only two previous studies ${ }^{18}$ that have investigated the immunomodulatory role of human colonic IEL on immunoglobulin production. Greenwood et $a l^{1}$ showed that IEL added to PBL in a ratio of 1:20 (IEL:PBL) stimulated IgA and IgM secretion, but increasing the ratio of IEL to PBL resulted in an increasing suppression of the immunoglobulin secretion. In contrast, Smart et $a l^{8}$ failed to show any effect. One possible reason for these discordant results is the difference in the purity of cell populations isolated in the two studies. The CD4/CD8 ratios of these isolated IEL populations were $0.06-$ $0 \cdot 14$ and $1 \cdot 21$ respectively, suggesting that the latter population was probably significantly contaminated with LPL. The data presented here (using an IEL preparation with a CD4/CD8 ratio similar to the Greenwood study) show that when IEL are used in a ratio of $1: 1$ with PBL or LPL,

$$
\begin{aligned}
& \text { - Control } \\
& \text { - Inflammatory } \\
& \text { bowel disease }
\end{aligned}
$$
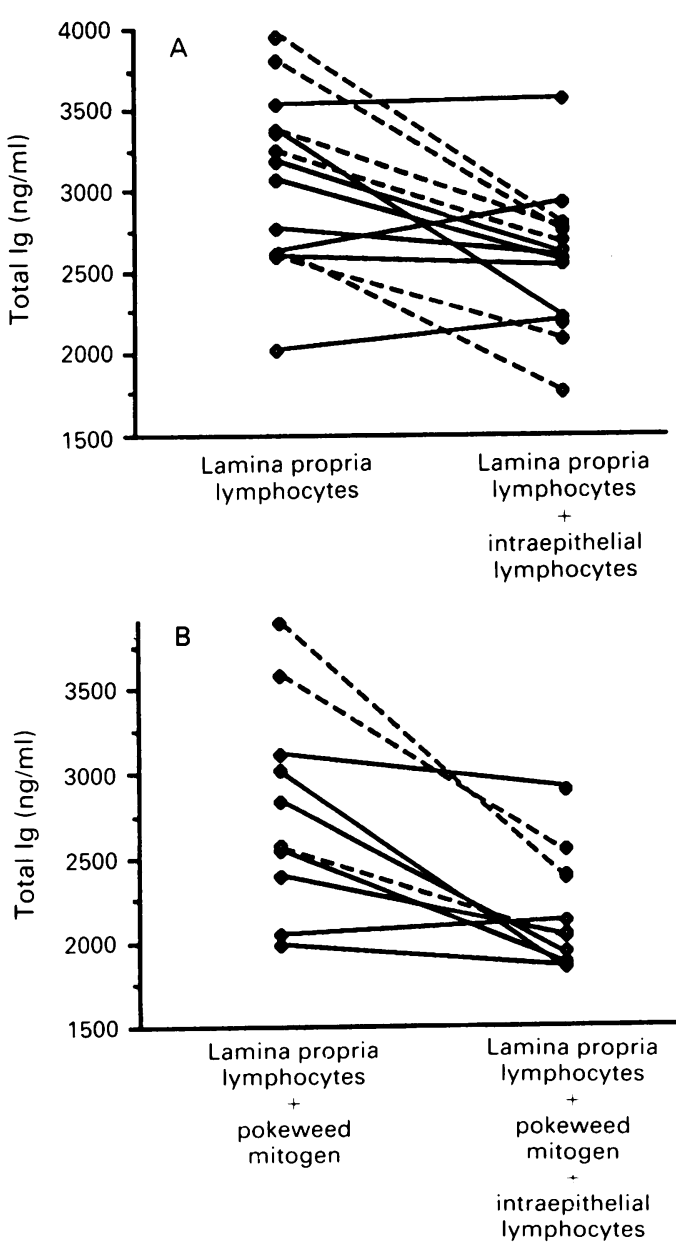

Figure 8: Effect of IEL on secretion of total Ig by lamina propria lymphocytes from eight controls and six patients with inflammatory bowel disease, cultured with or without pokeweed mitogen. (See legend to Figure 7.) 
Figure 9: Effect of the addition of $0.5 \mathrm{ml}$ of supernatant from 6 days' culture of intraepithelial to $5 \times 10^{\circ}$ peripheral blood lymphocytes from healthy volunteers on total immunoglobulin secretion. Peripheral blood lymphocytes were cultured for 9 days with or without pokeweed mitogen. The results expressed as $n g / m l$ of culture supernatant.

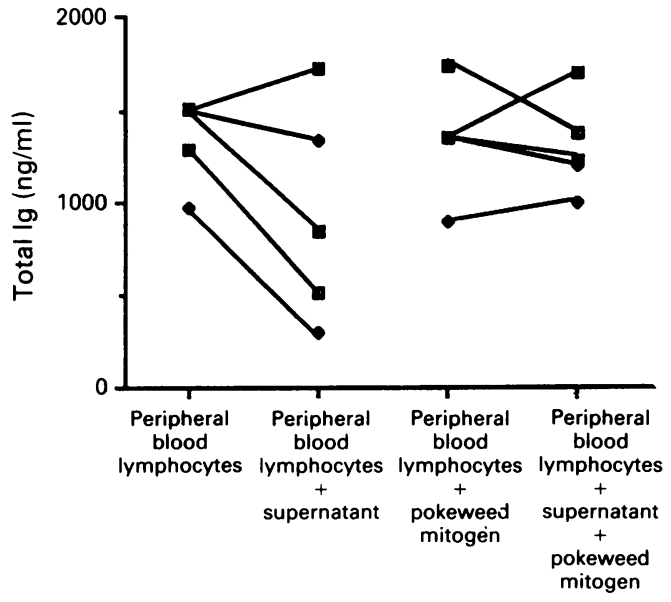

total Ig and IgA secretion is significantly suppressed.

Compared with controls, PBL from patients with inflammatory bowel disease produced significantly more total $\operatorname{Ig}, \operatorname{Ig} A$, and $\operatorname{Ig} M$. IgG synthesis was also higher in the inflammatory bowel disease group, but not significantly so. The addition of pokeweed mitogen failed to augment Ig synthesis in these patients, confirming previous observations. ${ }^{12}{ }^{13}$ The reason for this is not clear, but it could be that in inflammatory bowel disease the $\mathrm{B}$ lymphocytes are already in an activated state.

In addition to their ability to down regulate IgA synthesis, IEL suppress proliferative responses of LPL stimulated with phytohaemagglutinin, and the magnitude of suppression is similar in both. The mechanism of action of IEL mediated suppression is not known. The data presented here suggest that it may be caused by a soluble factor released by the IEL into the culture supernatant. Hoang et al made a similar observation and also found that IEL mediated suppression was CD8 dependent. ${ }^{6}$ A possible cytokine causing this suppression is interleukin 10 , which is known to down regulate a variety of immunological phenomena. ${ }^{14}$ Studies are currently in progress to characterise the responsible soluble factor.

IEL down regulate proliferative responses of autologous LPL in vitro, ${ }^{6}$ and this may be an important mechanism by which the gut tolerates the antigen rich environment of the lumen. This effect is also mediated by a soluble factor, which

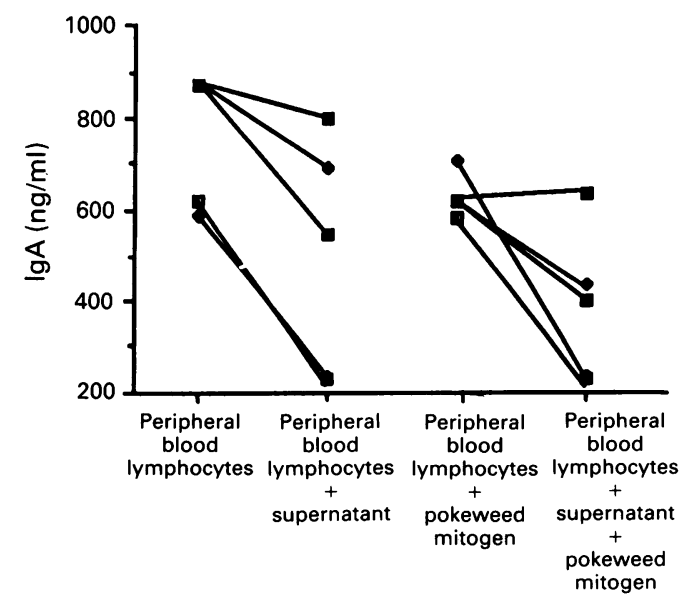

presumably acts locally in the superficial layers of the mucosa. It is possible, although not proved, that IEL are involved in cell 'trafficking' which would allow them to modulate immune reactions deeper in the lamina propria.

It is interesting that IEL seem to suppress selectively IgA synthesis: the relevance of this in vitro observation to mucosal immune events remains speculative, however. There are several possible explanations for this effect. IgA is the most predominant immunoglobulin spontaneously produced by $\mathrm{PBL}$ or LPL,${ }^{812}$ suggesting that IgA precursors are already in a stimulated state or are getting maximal $\mathrm{T}$ cell help in the culture. The addition of IEL, which are of suppressor phenotype, check the effect of helper $\mathrm{T}$ cells thus reducing the secretion of IgA by B cells. This view is supported by the fact that addition of a mitogen (pokeweed mitogen) to the culture medium tended to suppress IgA. This effect was possibly the result of pokeweed mitogen-stimulation of suppressor $T$ cells in PBL or LPL as removal of $\mathrm{CD} 8^{+}$cells from PBL using anti-CD ${ }^{+}$coated dynabeads abolishes this effect (unpublished observation). An alternative explanation could be that IEL are actually the down regulating $\mathrm{T}$ cells specific for IgA precursor cells, as it has already been shown that separate sets of $\mathrm{T}$ cells regulate IgA synthesis by $\mathbf{B}$ cells in the mouse, ${ }^{15}$ and possibly also in humans. ${ }^{1617}$

An alternative explanation for IEL's apparent ability to down regulate IgA secretion specifically is that, given the fact that both PBL and LPL spontaneously secrete more IgA than IgG or IgM, any non-specific suppressive effect of IEL is more likely to be reflected in reduced IgA secretion.

Immune activation in the gastrointestinal mucosa in inflammatory bowel disease is well documented. ${ }^{18}$ Given the fact that IEL have potent suppressive functions, a reasonable explanation for this mucosal activation is that there is a defect in IEL mediated suppression in inflammatory bowel disease. However, the present data do not support this view, as IgA synthesis was suppressed equally in control and inflammatory bowel disease subjects. It is possible that the defect in inflammatory bowel disease lies in the IEL's response to specific antigen(s). This is an even more attractive possibility in coeliac disease where the numbers of IEL are greatly increased and a specific antigen is known to be involved in the pathogenesis. Further studies are currently in progress to assess antigen specific suppression in IEL.

Dr G Sachdev was in receipt of a Commonwealth Medica Fellowship. We thank the Lee Placito Medical Fund for additional support. Dr Hoang was supported by the National Association for Colitis and Crohn's Disease.

1 Greenwood JH, Austin LL, Dobbin WO. In vitro characteriz ation of human intestinal intra-epithelial lymphocytes. Gastroenterology 1983; 85: 1023-35.

2 Selby WS, Jannosy G, Bofill M, Jewell DP. Intestinal lymphocyte subpopulations in inflammatory bowel disease: an analysis by immunohistological and cell isolation techniques. Gut 1989; 25: 32-40.

3 Cert-Bensussan N, Guy-Grand D, Griscelli C. Intra-epithelial lymphocytes of human gut: isolation, characterization and lymphocytes of human gut: isolation, characterizati

4 Ebert EC, Roberts AI, Brolin RE, Raska K. Examination of the low proliferative capacity human jejunal intra-epithelial lymphocytes. Clin Exp Immunol 1986; 65: 148-57.
Figure 10: Effect of the addition of $0.5 \mathrm{ml}$ of culture of intraepithelial lymphocytes to $5 \times 10^{5}$ peripheral blood lymphocytes from healthy volunteers on IgA secretion. (See legend to Figure 9.) 
5 Hirata I, Berrobi G, Austin LL, Karen DF, Dobbins WO Immunological characterization of intra-epithelial and lamina propria lymphocytes in control ileum and colon, and 603 .

6 Hoang P, Dalton HR, Jewell DP. Human colonic intraepithelial lymphocytes are suppressor cells. Clin Exp Immunol 1991; 85: 498-503.

7 Ebert EC. Intra-epithelial lymphocytes: interferon gamma production and suppressor-cytotoxic activities. Clin Exp Immunol 1990; 82: 81-5.

8 Smart CJ, Trejdosiewicz LK, Badr-el-Din S, Heatley RV. $\mathrm{T}$ lymphocytes of human colonic mucosa: functional and phenotypic analysis. Clin Exp Immunol 1988; 73: 63-9.

9 Cerf-Bensussan N, Jarry A, Brousse N, LisowarskaGronpierre R, Guy-Grant D, Briscelli C. A monoclonal antibody (HML-1) defining a novel membrane molecule antibody (HML-1) defining a novel membrane molecule present on human

10 Bull DM, Bookman MN. Isolation and functional characterization of human intestinal mucosal lymphoid cells. $\mathcal{f}$ Clin Invest 1977; 59: 1966-74.

11 Wu CC, Mahida YR, Priddle JP, Jewell DP. Immunoglobulin production by isolated intestinal mononuclear cells from patients with ulcerative colitis and Crohn's disease. Clin Exp Immunol 1989; 78: 37-45.
12 MacDermott RP, Geoffrey SN, Bertovich MJ, Seiden MV, Bragdon MJ, Beale MG. Alteration of IgM, IgG and IgA Bragdon $M J$, Beale $M G$. Alteration of $\mathrm{IgM}$, IgG and $\mathrm{IgA}$ synthesis and secretion by peripheral blood and intestinal
mononuclear cells from patients with ulcerative colitis and mononuclear cells from patients with ulcerative co
Crohn's disease. Gastroenterology 1981; 81: 844-52.

13 Drew PA, La Broody JT, Shearman DJC. In vitro immunoglobulin secretion by normal human intestinal lamina propria lymphocytes. Gut 1984; 25: 649.

14 Florentino DF, Bond MW, Mosmann TR. Two types of helper T-cells IV Th2 clones secrete a factor that inhibits cytokine production by Thl clones. F Exp Med 1989; 170: 2081-95.

15 Elson CO, Heck JA, Strober W.T cell regulation of murine Ig A synthesis. 7 Exp Med 1979; 149: 632-43.

16 Endoh $\mathrm{M}$, Sakai $\mathrm{H}, \mathrm{Nomoto} \mathrm{Y}$, Tomino $\mathrm{Y}$, Kaneshrige H IgA specific helper activity of T-cells in human peripheral blood. specific helper activity of T-cells

17 Mayer L, Fu SM, Kunkel HG. Human T-cell hybridoman secreting factors for IgA-specific help, polyclonal B cell activation, and B cell proliferation. $\mathcal{F} \operatorname{Exp} M e d$ 1982; 156: 1860-5.

18 Pallone F, Fais S, Squarcia O, Biancone L, Pozzilli P, Boirivant $M$. Activation of peripheral blood and intestinal lamina propria lymphocytes in Crohn's disease. In vivo state of activation and in vitro response to stimulation as defined by the expression of early activation antigens. Gut $1987 ; 28$ : $745-53$. 